no Centro de Estudos de Gestão Empresarial e Ambiental, que coordena na EAESP.

Muitas recomendaçôes da Agenda/Programa 21 não saíram do papel, como afirma o autor, e é de se esperar que as buscas de implementação se choquem com inúmeros obstáculos. Porém, o seu valor é sobretudo o de linha-mestra para a consecução do desenvolvimento sustentável, que foi se tornando a grande meta do conjunto das nações. É um enorme levantamento dos problemas que os seres humanos enfrentam nos tempos que correm e do que é possivel fazer para solucioná-los de uma formá global. A Agenda 21, transformada em Programa 21, torna o ideal de pensar em termos globais e agir em termos locais algo que pode e precisa ser instrumentalizado.

É preciso frisar que, por meio da Agenda 21, as comunidades e o poder locais foram consagrados em termos internacionais, o que, sem dúvida, é uma grande conquista, muito embora conquista muitíssimo maior seja a consolidação dessa consagração, por meio da implementação das políticas ali contidas.

Outro aspecto que saiu extremamente fortalecido foi a representatividade das organizaçöes năo-govemamentais, conhecidas como ONGs, e o pluralismo como visão necessária, quando se trata de meios e recursos, sobretudo no que se refere a tecnologia. O pluralismo aparece também na importância atribuída às comunidades locais e suas autoridades.

Empresas năo estatais nem privadas, as ONGs, quando cumprem efetivamente seu papel, caracterizam-se como instituiçŏes da sociedade civil, dirigidas para o interesse público. Muitas sảo as áreas passíveis de atuação das organizações não-governamentais. Devem ser instrumentos ágeis na defesa de direitos, na área ambiental, na produção de bens e serviços, na ajuda humanitúria, na área científica e em muitos outros domínios. O lugar das ONGs na Agenda 21 considerável e a expectativa parece ser a de que elas pos. sam funcionar também como eficientes instrumentos de cobrança em relação aos governantes. Para terminar. deve-se dizer que o pluralismo está afirmado em todas as áreas, e especialmente no plano tecnológico. Dois aspectos principais relacionam-se com esse fato: em primeiro lugar, o respeito à diversidade humana; em segundo lugar, o respeito às características únicas de cada ecossistema.

A Agenda 21, objeto deste livro, de forma alguma pode ser vista como um tratado, nem tampouco como uma espécie de convençäo com a capacidade de imposiçăo de vínculos obrigatórios ăqueles Estados tidos como signatärios. E um considerăvel plano de intençốes. Sua implementação depende do que se costuma designar vontade política dos governantes e da efetiva mobilização da sociedade.

\section{O FIM DOS EMPREGOS: 0 DECLÍNIO INEVITÁVEL DOS NÍVEIS DOS EMPREGOS E A REDUÇÃO DA FORÇA GLOBAL DE TRABALHO}

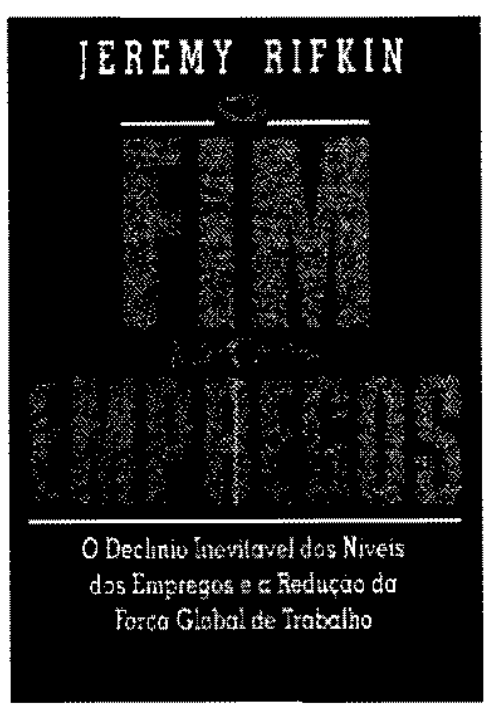

de Jeremy Rifkin

São Paulo: Makron Books, 1996, 348 p.

por Ana Paula Paes de Paula, Mestre em Administração Pública \& Governo pela EAESP/FGV e doutoranda em Sociologia no IFCHUUNICAMP.

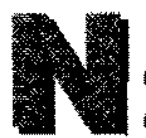
este livro Jeremy Rifkin procura dernonstrar que o desemprego tecnológico é a maior ameaça que a sociedade contemporânea irá enfrentar nos próximos anos, oferecendo evidências dessa inquietante perspectiva e da necessidade de um engajamento de todos os setores sociais na busca de alternativas para a resolução do problema.

De acordo com Rifkin, as evidências historicas negam o pressuposto neoclássico enunciado por Say de que a inovaçăo tecnológica estimula o crescimento econômico permanente e o emprego. A falsa idéía de que a oferta cria a demanda ja levou a humanidade à armadilha da Depressão de 29. Naquela época, a crise foi resolvida por meio do 
receituário keynesiano, mas acreditar que a mesma fórmula será capaz de combater o desemprego tecnológico, além do enfraquecimento da demanda do consumidor, é negar as novas realidades econômicas.

Isso porque a tendência de automação se mostra inexorável e atinge os três setores da economia: agrícola, industrial e de serviços. A mecanização do setor agrícola começou há cem anos e näo parou desde então: as novas tecnologias podem viabilizar uma fazenda totalmente automatizada daqui a vinte anos. No setor industrial, os modelos de flexibilização pós-fordistas possibilitaram um avanço ainda maior da substituiçăo da mão-de-obra humana por máquinas, o que tornarà o operariado um mero personagen da história no próximo século. Por quarenta anos o setor de serviços absorveu os desempregados das indústrias, mas o desenvolvimento das tecnologias de informação está réfreando essa tendência.

Rifkin argumenta que esse fenômeno estẩ associado ao fato de os empresários exibirem uma clara preferência pelo aumento da produtividade por meio de investimentos en bens de capital. pois, evitando a criação de novos postos de trabalho, eles se desincumbem dos encargos sociais e aumentam as margens de lucro. Isso está fazendo surgir um novo proletariado: as máquinas.

O autor afirma que as pequenas empresas não estäo conseguindo responder à procura por emprego, pois não crescem no mesmo ritmo em que aumenta o número de desempregados. Por outro lado, a globalizaçäo também não será suficiente para sustentar a demanda, por ser o desemprego tecnológico uma tendência mundial. Além disso, a fúria da automação não parece poupar nern mesmo os cargos mais qualificatos, como os de gerência média, passiveis de serem substituidos por sistemas de inteligễncia artificial.

Apoiado em um estudo da Federação Internacional dos Metalúrgicos de Genebra, Rifkin afirma que, dentro de trinta anos, menos de $2 \%$ da atual força de trabalho será suficiente para cobrir a produção de todos os bens necessários ao atendimento da demanda total. Na sua visão isso é provável porque ainda não surgiu nenhum novo setor econômico capaz de absorver a massa de demitidos, a não ser o setor da nova elite do conhecimento formada por analistas simbölicos (pesquisadores, engenheiros. arquitetos, advogados, consultores, produtores de filmes, diretores de arte, escritores, jornalistas...), que exclui os milhares de desempregados com baixa qualificaçăo.

A inevitabilidade do desemprego estrutural coloca a humanidade diante do dilema de viver em uma era luminosa, na qual a utopia do ócio se tornará possível no paraíso criado pela tecnologia, ou em uma era sombria pautada pela violência e convulsẵo social. $O$ autor acredita que o futuro depende exclusivamente de como os ganhos de produtividade da Era da Informaçầo seräo distribuídos.

Para 0 autor, a não-distribuiçảo dos ganhos auferidos com a automaçăo está levando a uma grande concentração de ren- da, que é agravada pela irresponsabilidade social da classe empresarial, uma vez que esta só age no sentido de aumentar ainda mais os índices de desemprego e a informalização do mercado de trabalho, o que gera inevitáveis tensôes sociais.

Rifkin se dedica então a mostrar como a renda poderia ser redistribuída. Em primeiro lugar ele aponta a necessidade de uma reestruturação da jornada de trabalho e dos níveis salariais. A redução da jornada de trabalho poderia causar um impacto positivo nos índices de emprego, especialmente se fosse generalizada para todo setor, evitando que a classe empresarial recusasse a proposta atraves do argumento da perda de competitividade. Paralelamente, uma política de desestímulo ao pagamento de horas extras minimizaria as tentativas de sabotar a redução da jornada de trabalho. Para assegurar a demanda por produtos e serviços seria preciso aumentar ou manter os níveis salariais, proposta que naturalmente sofreria oposições por parte do empresariado e que poderia ser solucionada com uma negociação por um salário menor e a contrapartida de participaçăo nos lucros.

Por outro lado, Rifkin assinala a necessidade de se estabelecer um novo pacto social, uma vez que nem o Estado e nem o mercado têm se mostrado capazes de satisfazer as necessidades básicas da humanidade. Nesse pacto, o autor vislumbra a participaçấo do Terceiro Setor, que poderia absorver o tempo ocioso da população economicamente ativa e a força de trabaiho dos desempregados por meio da prestafão voluntária de serviços sociais. Na visão do autor, o Estado poderia apoiar esse novo pacto com um salário indireto para os empregados que doassem seu tempo, atravěs de um mecanismo de dedução no imposto de renda por hora de trabalho voluntário e de um salário social para os desempregados que se dispusessem a ajudar sua própria comunidade. Isso viabilizaria um projeto de renda básica anual assegurada pelo governo e vinculada ao serviço comunitário que desenvolveria o espírito de comunidade e a economia social. Os fundos para o programa seriam obtidos pela liberação de renda que ocorreria com a redução da burocracia pública do serviço social, pela eliminação de subsídios concedidos às corporações transnacionais e pela criação de um imposto sobre valor agregado que transferisse os ganhos da economia high-tech dos fornecedores e beneficiários para os excluídos dos avanços tecnológicos.

Após discutir essas possíveis alternativas para a minimizaçăo do desemprego e de seus efeitos, Rifkin encerra o livro questionando se o Terceiro Setor, que surgiu no vácuo deixado pelo recuo dos setores público e privado nos assuntos comunitärios locais, poderá dar conta đa missâo de absorver a força de trabalho deserdada, transformando a economia de mercado em uma economia social.

O livro proporciona uma leitura estimulante para administradores, economistas, sociologos e pesquisadores de questôes como a reestruturação produtiva, o desemprego estrutural e a revolução tecnológica. É também recomendável para estudiosos de temáticas relacionadas ao Terceiro Setor. $\square$ 